\title{
EL PALAO DE ALCAÑIZ Y EL BAJO ARAGÓN DURANTE LOS SS. II Y I A.C.
}

\author{
POR \\ JOSÉ ANTONIO BENAVENTE SERRANO \\ Taller de Arqueología de Alcañiz \\ FRANCISCO MARCO SIMÓN \\ Universidad de Zaragoza \\ PIERRE MORET \\ Casa de Velázquez
}

PALABRAS CLAVE: Iberos, romanización, identidad, Ausetanos, Osicerda.

KEY WORDS: Iberians, Romanization, identity, Ausetani, Osicerda.

\section{RESUMEN}

Estas líneas tienen como objetivo valorar el papel y la importancia que pudo tener la ciudad ibero-romana de El Palao en el contexto bajo-aragonés de los ss. II y I a.C. Se analizan las características de la misma, el interés de su taller escultórico como vehículo de perpetuación de la memoria cultural, el ascenso de la ciudad -que parece favorecido por la propia Roma- y, por último, se considera la posibilidad de su identificación con Usekerte/Osicerda.

\section{SUMMARY}

The evaluation of the role of El Palao in the context of the Bajo Aragón during the 2nd. and 1st. centuries is the aim of this paper, which focuses on the characteristics of this Ibero-roman town, the interest of its sculptures and reliefs as expressions of the ancestrai indigenous culture, its politica rising as induced by Roma, and the possibility of its identification with Usekerte/Osicerda.

El Palao es un yacimiento situado a unos $5 \mathrm{~km}$ al suroeste de Alcañiz (Teruel), sobre un cerro amesetado - muy próximo a la carretera de Alcolea del Pinar a Tarragona- cuyo punto más alto alcanza los $428 \mathrm{~m}$, unos 55 por encima de la plana circundante. En estos momentos se reanudan las actividades arqueológicas en el yacimiento en el marco de un programa de investigaciones desarrollado por la Casa de Velázquez, el Taller de Arqueología de Alcañiz, la Universidad de Zaragoza y la Universidad de Toulouse ${ }^{~}$. El estado de la cuestión que aquí presentamos es, por tanto, provisional, y es de esperar que los nuevos hallazgos modificarán de forma sustan-

\footnotetext{
' Proyecto coordinado por los tres firmantes de este artículo. La primera campaña ha tenido lugar en junio-julio del 2003
}

cial nuestro conocimiento del yacimiento, que en la actualidad se basa en los datos fragmentarios de las excavaciones antiguas de Vicente Bardavíu y Raymond Thouvenot (1930), de las llevadas a cabo por la Universidad de Zaragoza entre 1978 y 1986 (Marco Simón, $1980 ; 1983$; 1985) y de diversos hallazgos fortuitos, especialmente de esculturas en piedra y estelas decoradas (Marco Simón, 1976; 1978 a; 1978 b).

El inicio de la ocupación de El Palao parece situarse en época prehistórica, a juzgar por algunos hallazgos dispersos aparecidos fuera de contexto estratigráfico (Bardavíu, 1926; Benavente et al., 1987). En las excavaciones realizadas hasta el momento no se han encontrado materiales o estructuras que indiquen, con seguridad, una ocupación ibérica anterior a la llegada de los romanos, si bien las excavaciones en curso (junio-julio del 2003) han revelado la existencia de un poblado de la primera Edad del Hierro en la parte más alta del cerro. Diversos hallazgos de cerámica de barniz negro indican una ocupación generalizada a partir de finales del siglo III o inicios del II a.C., coincidiendo, por tanto, con el momento de la conquista y ocupación romana de estos territorios, aunque no podemos todavía fechar con precisión el momento en que El Palao se vertebra definitivamente como asentamiento urbano. El yacimiento debió de ser abandonado, al menos parcialmente, a fines del período julio-claudio, en torno al 70 d.C. (Marco Simón, F. et alii, 2003). Pero lo que nos interesa tratar aquí es la fase republicana de la vida de la ciudad.

\section{EL OPPIDUM DE EL PALAO: UN ASENTA- MIENTO URBANO ATÍPICO}

No parecen existir dudas para afirmar que el poblado de El Palao constituye el asentamiento urbano de mayor extensión y de mayor importancia del sec- 
tor central del Bajo Aragón -entre los ríos Martín y Matarraña, afluentes de la margen derecha del Ebro- durante la etapa ibero-romana. Algunas de las características de este importante asentamiento son especialmente ilustrativas. Así, un emplazamiento muy estratégico que domina topográfica y visualmente una gran extensión de terreno, en una zona relativamente llana (excepto el poblado del Cabezo de Alcalá de Azaila, no se conoce en el Bajo Aragón un asentamiento ibero-romano de semejantes dimensiones y que presente unas características tan evidentes de dominio del territorio circundante); la dispersión de restos de muros y estructuras en una superficie de unas 3 hectáreas y presencia de numerosos restos de construcciones en los alrededores del mismo; la existencia de varios templos, según $\mathrm{V}$. Bardavíu y R. Thouvenot, y de grandes construcciones públicas como la cisterna, el foso o camino de entrada y un edificio de dos naves, parcialmente excavado en la roca, que se sitúa en la extremidad nororiental del cerro (fig. $1, \mathrm{n}^{\circ} 2$ ); la aparición de elementos escultóricos de bulto redondo únicos en este sector del Valle del Ebro así como de algunas singulares estelas ibéricas.

En el estado actual del yacimiento se observan en superficie algunos indicios de fortificaciones, aunque, en general, poco claros y de escasa entidad. Entre estas estructuras habrá que mencionar el posible foso (también camino de acceso) que prácticamente divide en dos al poblado. Según Bardavíu (1926), este foso: «separa la Acrópoli de la Ciudad, tiene noventa y cinco metros de longitud, de siete a diez de anchura y tres de elevación». La estructura es fácilmente apreciable a simple vista, así como en el levantamiento planimétrico (fig. 1), y parece constituir el tramo final del camino de acceso al poblado a través de una rampa o subida por la ladera este del cerro ${ }^{2}$. En relación con este foso o camino de entrada puede mencionarse también un posible torreón de planta ovalada de unos siete metros de diámetro que se sitúa en un punto elevado al Noroeste del mismo, desde el que se controla en altura la mayor parte de su recorrido ${ }^{3}$.

Es asimismo interesante la existencia de una gran cisterna, en el sector suroriental del poblado, de planta trapezoidal rectangular y una superficie

\footnotetext{
${ }^{2}$ Este tipo de fosos o caminos excavados en la roca para el acceso a poblados existen también con claridad en otros yacimientos ibéricos o ibero-romanos del Bajo Aragón como Alcañiz el Viejo, Tiro de Cañón, Cabezo del Moro y La Caraza en Alcañiz, o San Cristóbal en La Codoñera.

${ }^{3}$ Después de redactar estas líneas los primeros resultados de la campaña de excavación en curso indican que el torreón circular pertenece a un asentamiento mucho más antiguo (I Edad del Hierro o Ibérico Antiguo).
}

aproximada de 80 metros cuadrados, que ha sido objeto de estudio en detalle en una reciente monografía (Marco Simón et alii 2003). El cerro de El Palao se emplaza a una distancia de unos $3 \mathrm{~km}$ del curso del río Guadalope, aunque muy cerca de una extensa área endorreica y de algunas pequeñas fuentes naturales que todavía hoy se emplean. La necesidad de agua en un asentamiento de estas características y tan alejado del curso del río justifica la existencia de un gran aljibe para suministro diario de su abundante población. Por otra parte, la construcción de esta obra, de indudable carácter público y monumental, debió conllevar una organización social y de poder claramente establecida, así como una planificación previa del conjunto urbano que incluiría los caminos de acceso, el posible foso y torreón, una posible acrópolis con templos y, en fin, la propia ordenación urbanística del cerro planificada en su conjunto.

Aunque se ha realizado un detallado levantamiento planimétrico y altimétrico de El Palao y de sus estructuras visibles en superficie, no se dispone todavía de la información suficiente para conocer la trama urbana de este gran asentamiento, ordenada a partir de la construcción de varias calles en sentido oeste-este cuyo trazado aparece todavía muy indefinido.

Entre las estructuras y edificios de carácter público podemos mencionar la existencia de tres posibles templos en el sector Este del cerro donde, según V. Bardavíu (1926), debió emplazarse la acrópolis. Uno de ellos, la estructura llamada «templo ibérico» por Thouvenot (Bardavíu y Thouvenot, 1930, 62) (fig. 1, $\mathrm{n}^{\mathrm{o}} 7$ ) tendría probablemente una función artesanal y no cultual, pero se puede aceptar como probable - a la espera de la reanudación de las excavaciones- la función religiosa o en todo caso pública del conjunto de estructuras monumentales situado en la parte más elevada del sector este (Bardavíu y Thouvenot, 1930, 44-48) (fig. 1, $\mathrm{n}^{\circ} 2$ ).

Sin embargo, el yacimiento de El Palao presenta diversos caracteres atípicos que lo alejan del modelo corriente de los oppida republicanos del valle del Ebro. A diferencia de lugares como Contrebia Belaisca, La Cabañeta de El Burgo de Ebro, La Caridad de Caminreal, Salduie o el Cabezo de Alcalá de Azaila, en el El Palao no han salido a la luz hasta el momento edificios que respondan a una planificación típicamente romana o cuya concepción fuera fuertemente influida por un modelo itálico: ni casa con patio, ni templo in antis, ni termas, ni horreum. No obstante, la aparición de nuevos materiales, como el capitel corintio mencionado más abajo, pueden llevarnos a matizar esta visión.

El urbanismo parece irregular y se aleja del mo- 


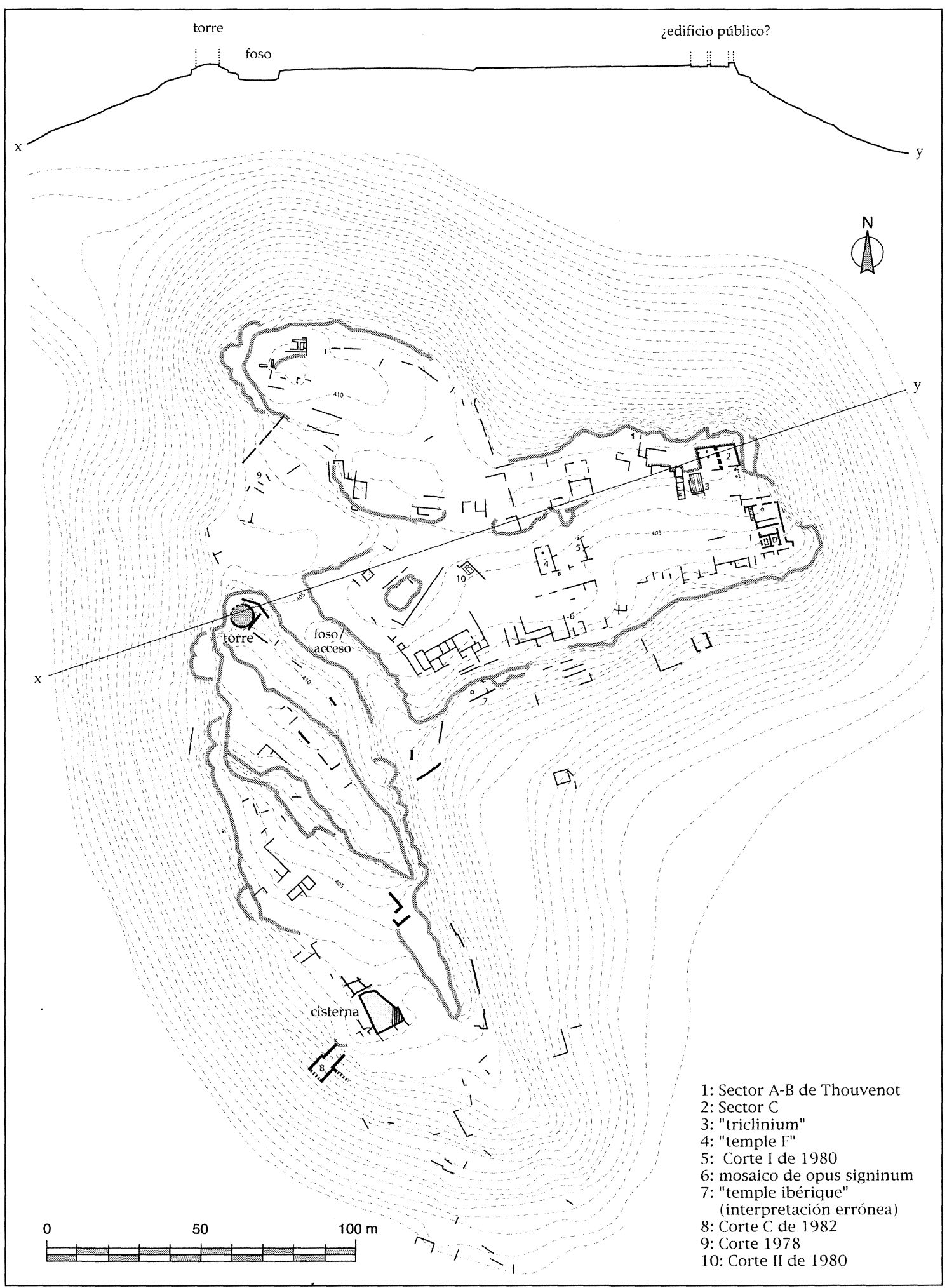

Fig. 1. Plano del yacimiento de El Palao, según planimetría de Benavente et alii 1991, con indicación de las zonas excavadas anteriormente a la campaña del 2003. 


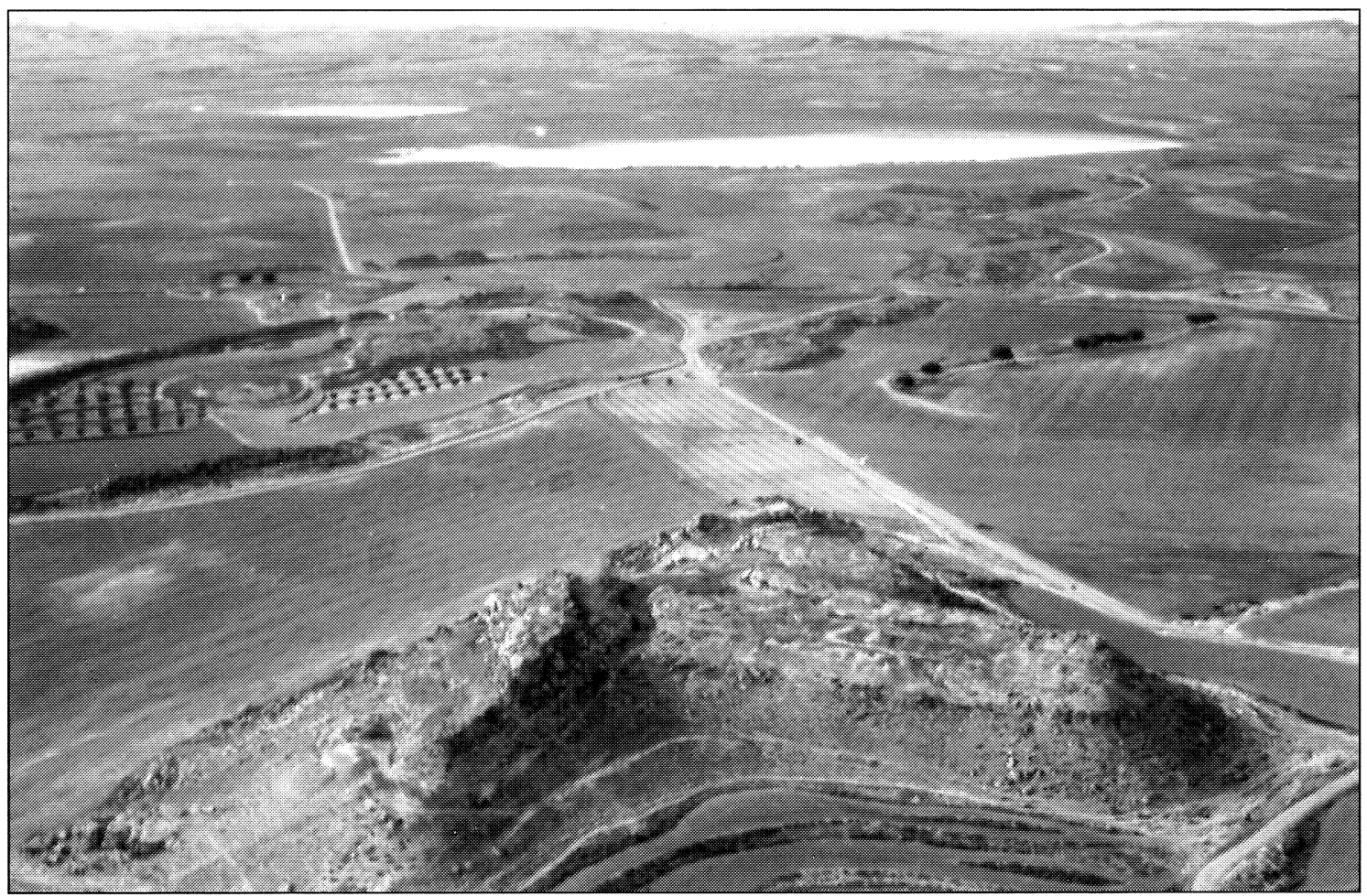

Fig. 2. Vista aérea del yacimiento de El Palao.

delo ortogonal presente, por ejemplo, en La Caridad de Caminreal (Teruel) (Vicente et alii, 1986). Con excepción del torreón arriba mencionado, las informaciones sobre un posible sistema defensivo son escasas. No parece que existiera una muralla en el estricto sentido de la palabra. Por el contrario, la colina está partida en dos por el camino de acceso tallado en la roca, que podía hacer el papel de foso defensivo. Este foso no se sitúa al exterior, en torno a la zona habitada, como en La Cabañeta de El Burgo de Ebro o en La Corona de Fuentes de Ebro, sino que divide el oppidum mismo en dos partes desiguales (más extensa la oriental y más reducida la occidental). Trabajos futuros nos indicarán en qué medida esta separación se corresponde con una repartición rigurosa de las funciones urbanas. Todo cuanto puede decirse es que el único sector fortificado se encuentra en la zona occidental: es en ella donde se ubica una poderosa torre de defensa y donde se ha excavado la cisterna de gran capacidad, vital para los habitantes en caso de asedio. En la otra zona, al este del foso, se encuentran los barrios de habitación y, probablemente, los edificios religiosos.

El esquema que se adivina a partir de estos elementos se aleja del modelo urbanístico romano, centrado en el foro y sus monumentos públicos. Se tie- ne más bien la impresión de estar ante una lógica de disociación entre una acrópolis fortificada al oeste y una zona de hábitat y de artesanado al este. Este tipo de urbanismo se corresponde más con un modelo aristocrático relativamente arcaico en su concepción que con un modelo cívico a la romana. Como más abajo se verá, un modelo parecido se atestigua en otros yacimientos bajoaragoneses de época republicana, como La Caraza de Valdevallerías y la Torre Cremada de Valdeltormo.

\section{LA ESCULTURA Y LA MEMORIA CUL- TURAL}

La escultura y los relieves en piedra constituyen otra originalidad de El Palao en relación con los oppida del valle medio del Ebro (Marco, 1976; 1978a). El número de las estelas decoradas características del Bajo Aragón ha ido aumentando desde los 17 ejemplares catalogados en 1951 (Fernández Fuster, 1951) hasta las casi tres decenas alcanzadas con los hallazgos posteriores ${ }^{4}$. En el mapa de dis-

${ }^{4}$ Además de Alcañiz (El Palao, Valdevallerías), Oliete, Caspe, Chiprana, Valdetormo, Valderrobles, Cretas Calaceite y Mas de las Matas son las localidades donde han aparecido 
persión de dichas estelas (fig. 6) destaca claramente la centralidad de El Palao de Alcañiz, donde ha aparecido el mayor número de ejemplares, cinco (incluyendo un pequeño fragmento inédito ${ }^{5}$ ), que además constituyen, junto con los de Caspe, el formato mayor -entre 70 y $60 \mathrm{~cm}$ de anchura- de entre las estelas ibéricas, que por lo general se sitúan por debajo de los $50 \mathrm{~cm}$ de anchura (Izquierdo y Arasa, 1999, 279).

Los motivos iconográficos de estos monumentos (escenas bélicas con jinetes, caballos, lanzas o escudos) constituyen una magnífica concreción de una ideología y de un ethos aristocrático ancestral, en la que la virtus guerrera constituye el elemento canalizador de la autorrepresentación de las élites. Dos elementos destacan en el subrayado de la sublimación agonística del difunto: el caballo y las lanzas.

Particular interés tiene una de las estelas de El Palao, con representación de un jinete con escudo circular (caetra) y lanza sobre el cadáver yacente de un enemigo, una gran mano derecha invertida a la izquierda - auténtico tropaeum - y, rodeando al caído, tres buitres y un cánido (fig. 3$)^{6}$. Tres de las otras estelas halladas en el yacimiento exhiben las características lanzas, que en este caso son faláricas provistas de regatones (Marco, 1976, figs. 2-5 y láms. II-III; id., 1983, lám. 9), y es típica del taller de El Palao una decoración a base de bandas con motivo geométrico de líneas en zig-zag alternando con meandros, así como motivos en SSS y en forma de gancho que parecen estilizaciones de elementos vegetales y que aparecen igualmente en la cerámica de Azaila o de Llíria/Edeta.

La representación de las lanzas en las estelas de la región bajoaragonesa remite claramente al pasaje de Aristóteles (Pol. VII, 2, 11; 1324b) sobre la belicosidad de los iberos, que clavaban en torno de la tumba del guerrero muerto tantas lanzas como individuos hubiese matado. La Política la escribe el Estagirita en el tercer cuarto del s. IV a.C., por lo que, si pensamos en una cronología para nuestras estelas

estas piezas (Izquierdo y Arasa, 1999, 278; Burillo, 20012002, 177).

${ }^{5}$ El fragmento, partido en dos trozos, mide $(26) \times(15,5) \times$ $7 \mathrm{cms}$. y corresponde a una parte del borde de una estela con una orla que contiene unos motivos incisos en forma de $\mathrm{S}$ como los representados en el campo de una de las ya conocidas (Marco, F. 1976, 78, fig. 3 y lám. II, 2), sólo que esta vez enlazados verticalmente entre dos líneas incisas.

${ }^{6}$ Véase, por último, la revisión que, a partir del monumento de La Vispesa (Tamarite de Litera, Huesca), fechado recientemente en las primeras décadas del s. II por criterios paleográficos (Rodríguez Ramos, 1997), ha llevado a cabo Silvia Alfayé (e.p.) de este tipo de iconografías - y, en concreto, de la gran estela de El Palao-, que interpreta como la expresión de unos rituales de aniquilación del enemigo vencido.

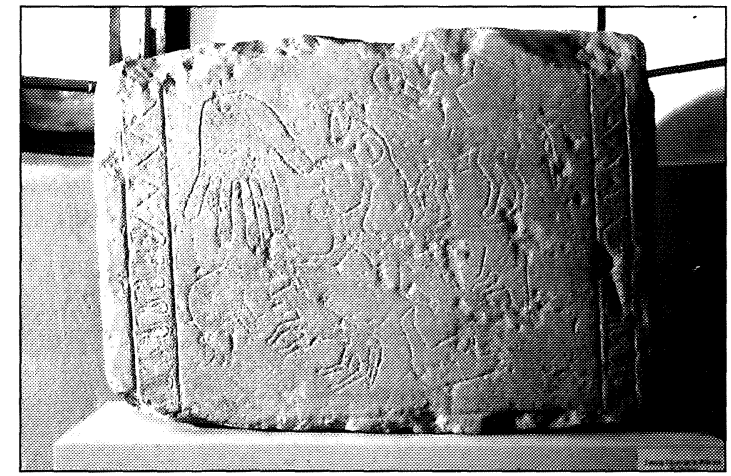

Fig. 3. Estela de El Palao, con representación de un jinete armado, el cadáver yacente de un enemigo al que rodean tres buitres y un cánido, y una gran mano cortada (Taller de Arqueología de Alcañiz).

del s. II o I a.C., existe un desfase de dos siglos entre la noticia literaria y lo que parece su confirmación arqueológica. Las estelas, más que reflejo de la actividad de los indígenas como auxiliares de los ejércitos romanos (F. Beltrán, en Beltrán, F., MartínBueno y Pina Polo, 2000, 48), supondrían la «petrificación» de una costumbre funeraria muy anterior, que, como ha indicado F. Quesada (1994, 365-66), parece confirmada por la arqueología ${ }^{\text {. }}$.

En resumen, si bien las estelas del Bajo Aragón pueden ser evaluadas (lo mismo que la escritura que las acompaña en los ejemplares de Cretas - Mas de Madalenes- o de Caspe) como un ingrediente expresivo del proceso de romanización, revelan sin embargo un universo simbólico tradicional. Durante el período ibérico tardío, lejos de anularse la peculiaridad de la cultura ibérica, encontramos uno de los momentos de máximo esplendor de la misma, como muestran la difusión de la escritura indígena y las acuñaciones monetales, las decoraciones de las cerámicas o las de las estelas (Burillo, 2002, 205), y esta es una característica que se observa igualmen-

\footnotetext{
${ }^{7}$ En efecto, teniendo en cuenta la significativa aparición de regatones y de lanzas clavadas verticalmente en el suelo de diversas tumbas, tanto en el mundo hispano-céltico (E1 Raso de Candeleda - Ávila-, Prados Redondos - Guadalajara-) como en el ibérico (La Oriola de Amposta, Camí del Bosquet -Valencia-, El Cigarralejo de Mula - Murcia- sobre todo), cabe pensar que las estelas bajoaragonesas expresan las imágenes de la memoria de unos rituales funerarios ancestrales atestiguados en amplias zonas de la Península (Quesada, 1994, 365-366), conteniendo un valor simbólico sobreañadido que está presente en la estela de Ampurias, que representa en ambas caras un soliferreum enrollado sobre sí mismo con la punta triangular hacia abajo (Domínguez Monedero, 1994), en imagen relacionable con la inutilización ritual de lanzas en diversas necrópolis peninsulares, y también en la gran lanza de bronce «de parada» hallada en las excavaciones de Botorrita y fechable en el s. II a.C. (Villar et alii, 2001, fig. 27)
} 
te en los códigos expresivos de la Hispania indoeuropea.

La ausencia de contexto arqueológico dificulta una valoración de la función de estos monumentos, cuya iconografía ${ }^{8}$ remite, con todo, a un horizonte claramente funerario, quizás complementado con un carácter conmemorativo a través del traslado o remoción de las piezas (así, Burillo, 1992, 577-78), en las que se ha querido ver emblemas de grupos locales concentrados en determinados puntos como marcadores territoriales, ya en el contexto de la conquista romana (Galán, 1994). En cualquier caso, la inmensa mayoría de las estelas antiguas que conocemos en la Península Ibérica (y no sólo en ella), desde las características del suroeste en el Bronce Final hasta las de época romana, ha aparecido fuera de contexto funerario, como elementos reutilizados.

Como más abajo se verá, sobre la base de la propuesta de P. Jacob (1987-88) F. Burillo ha propuesto situar a los ausetanos del Ebro ${ }^{9}$, homónimos de los de la zona catalana subpirenaica, entre el valle del río Martín y los puertos de Beceite, indicando además que las estelas bajoaragonesas constituirían un indicador cultural «supracívico» de dicho pueblo (Burillo, 2001-2002; 2002). A partir de estos supuestos, F. Quesada (1999-2000) ha llamado recientemente la atención sobre la existencia de unos paralelos iconográficos para los monumentos bajoaragoneses en estelas de Cataluña. Tres de ellas, una de Rubí (Barcelona) y dos del poblado de Sant Sebastià de la Guarda (Palafrugell, Gerona) exhiben el típico motivos de los frisos de lanzas que hallamos en muchos ejemplares bajoragoneses, mientras que en Tona, localidad de los alrededores de Vic, se halló una estela con escena bélica de combate entre dos guerreros, que, como acertadamente han señalado Garcés y Cebrià (e.p.), constituye un ejemplo del topos del combate singular que ilustra el episodio de Corbis y Orsua ante Escisión narrado por Livio $(28,21,1)^{10}$. Pero la aparición en el verano del año 2000 de un par de estelas ibéricas con epígrafe en Baetulo (Badalona), una de ellas con las típicas lanzas -ya conocidas en otro

${ }^{8} \mathrm{O}$ también la epigrafía en el caso de la estela del Mas de Madalenes (Cretas): kalun.seltar, cuyo segundo elemento significaría «tumba» (Untermann, J., 1990, 194).

${ }^{9}$ Los pasajes de Livio que los mencionarían son los siguientes: XXI, 61; XXVI, 17; XXIX, 1; XXXIV, 20; XXXIX, 56.

${ }^{10}$ Esta estela ausetana, datable entre los ss. III y II a.C. (Garcés y Cebrià e.p.), parece orientarse claramente, como las otras representando las lanzas, hacia el Bajo Aragón, y en concreto hacia la gran estela de El Palao, tan cercana temáticamente - además del monumento de La Vispesa- a la estela gigante de Zurita (Cantabria) (Marco, 1978, 108 y lám. 2). ejemplar hallado en la misma localidad- y datada por criterios paleográficos entre 150 y 75 a.C. (Comas, Padrós y Velaza, 2001), es decir, en la misma época que la mayoría de las estelas bajoaragonesas, amplía considerablemente al espacio layetano la geografía de estas estelas de lanzas, lo que, paralelamente, reduce la pertinencia de la propuesta establecida por Quesada en el sentido de considerar este motivo iconográfico como expresión de la identidad cultural común a los ausetanos del Ebro y los de la zona catalana, para la que en realidad sólo contamos con el ejemplar de Tona. Ello no obsta para que, efectivamente, los paralelos más claros para las estelas del Bajo Aragón se encuentren en el nordeste catalán, pues las estelas antropomorfas de Nogueruelas (Teruel) y de Ares del Maestre (Castellón), de un tamaño mucho mayor (la primera, que tiene inscripción, alcanza los 135 cms.) y datables en los ss. IV-I a.C., se relacionan con ejemplares mucho más meridionales como los de Altea (Alicante) o Espejo (Jaén) (Izquierdo y Arasa, 1999, 272-273).

La escultura en piedra de El Palao, representada por los dos caballos de gran tamaño, uno de ellos con cabeza, y por una cabeza humana, remite a un horizonte simbólico similar al de las estelas. La existencia de esta escultura en piedra es un fenómeno particularmente original, pues no tiene precedentes en el valle del Ebro en época ibérica plena, con la excepción del león de Monzón (Huesca) (Marco y Floría, 1986). Sus orígenes y su significación están lejos de una segura explicación. En cualquier caso, los caballos de El Palao apuntan técnicamente más hacia la escultura animalística meseteña de los verracos, especialmente uno de los ejemplares (Marco, 1978b). Pero basta comparar las esculturas en piedra de El Palao con el grupo escultórico en bronce de Azaila, completamente romano en su inspiración, para comprender que las élites urbanas de ambos oppida, que con probabilidad encargaron estas obras, no se referían, a pesar de su proximidad, a los mismos modelos.

En El Palao se halló asimismo en 1990 una cabeza masculina de arenisca, inédita hasta la fecha (figs. 4 y 5). Mide $17 \mathrm{~cm}$ de altura, por 16 de anchura - en la parte superior de las orejas del personaje- y $15 \mathrm{~cm}$ de grosor máximo. Se trata de una pieza de tosca factura, pero con indicación precisa de los detalles anatómicos (línea indicando el arranque del cabello, oídos prominentes, nariz recta, ojos saltones y almendrados, con indicación de la pupila mediante una incisión central, y boca de labios gruesos, en relieve como el resto de los órganos faciales, entreabierta para dar una expresión 


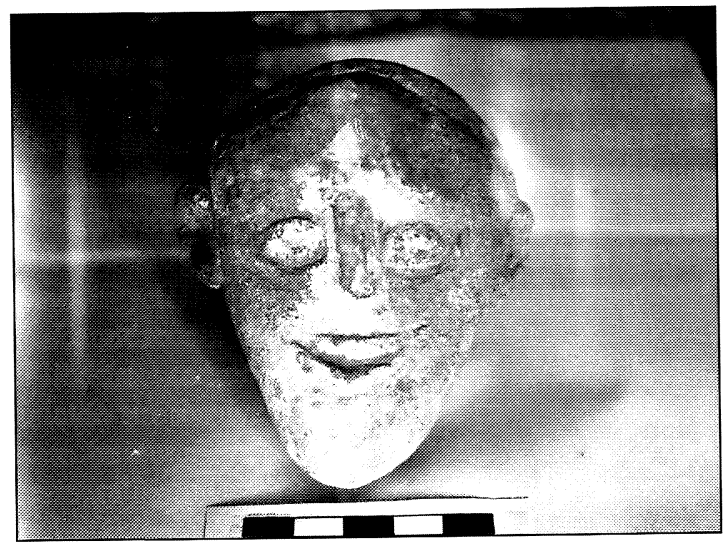

Fig. 4. Cabeza humana en piedra arenisca procedente de El Palao (colección particular).

que recuerda a determinadas figuras del arcaísmo griego o del arte etrusco). La escultura se conserva intacta, no presenta rotura alguna y es posible que estuviera destinada a engastarse en una oquedad practicada en un soporte vertical, al modo de las conocidas representaciones de los santuarios celtoligures de la Provenza. Su paralelo más cercano es otra cabeza, muy similar, hallada en las inmediaciones de la ciudad de Segeda (Durón de Belmonte, Zaragoza), capital de los belos. Perteneciente a la colección Samitier, esta cabeza se conserva en el Museo de Zaragoza, parece fecharse en el s. II a.C. (Sáiz, 1992) y sus dimensiones $(13,5 \times 9,5 \times 3,4$ $\mathrm{cm})$ son inferiores a las de la cabeza de El Palao. También en un pila bautismal de la ermita de la Virgen de Cabañas (La Almunia de Doña Godina, Zaragoza) se colocaron dos cabezas procedentes quizás de la cercana ciudad celtibérica de Nertobriga. Miden entre 13-14 cms. de alto por 12 de ancho, y especialmente una de ellas se asemeja estrechamente a la del Palao, pues presenta igualmente la boca entreabierta (Medrano y Díaz, 2000, 172 174, figs. 1-4). Si bien en el nordeste catalán se documenta alguna manifestación interesante del motivo (desde las cabezas de la muralla de Tarragona al monumento de Sant Martí Sarroca), es hacia el mundo hispanocéltico hacia donde hay que buscar los paralelos (Almagro-Gorbea y Lorrio, 1992) de la cabeza de El Palao, en la que no necesariamente hay que ver la manifestación icónica del conocido ritual de las «cabezas cortadas» del enemigo documentado para el mundo galo a partir de los datos de Posidonio de Apamea (Diodoro, 5, 9, 5, y Estrabón, 4, 4, 5), y que tan bien expresan diversas fíbulas de jinete y caballito en el mundo hispano (Almagro-Gorbea, 1999), sino la expresión de un

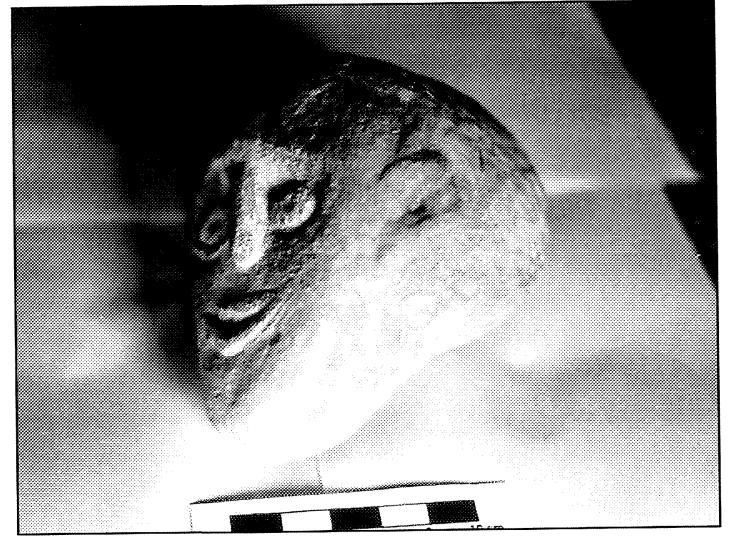

Fig. 5. Cabeza humana de El Palao (colección particular). Vista lateral.

horizonte semántico de gran riqueza y polivalencia que se fundamenta en la consideración de la cabeza como sede de la vida y que se manifiesta no sólo en la vejación del enemigo que conlleva el ritual de decapitación, sino también en el carácter profiláctico y sagrado de la cabeza como tal (Marco, 1994, 381-383; Sopeña, 1995), que explica su aparición como expresión de la divinidad, del espíritu del muerto o, en cualquier caso, su omnipresencia en las manifestaciones culturales de los celtas.

En resumen, tanto el urbanismo como el desarrollo de una iconografía particular hacen de El Palao un caso atípico, en el que la influencia romana aparece de forma muy discreta, en tanto que las tradiciones indígenas conocen un desarrollo original, que se manifiestan a través de los talleres escultóricos, mientras que en oppida ibéricos tan cercanos como Azaila o El Cabezo de La Guardia de Alcorisa ese acervo se plasma especialmente a través de un lenguaje icónico de importancia también excepcional, pero desarrollado sobre soporte cerámico.

No obstante, hay un elemento que sí responde a un modelo cultural helenístico-romano, en el supuesto de que, como parece, proceda de El Palao. Se trata de un capitel corintio de arenisca, del que se conserva la zona superior del equino y parte del ábaco, que se inscribe en la tradición de los capiteles corintio-itálicos que siguen el modelo tardorrepublicano del llamado «Segundo Triunvirato». Los paralelos más próximos de este capitel, intermedio entre el corintio-itálico y el normal, son productos del taller de Barcino, y la cronología del de El Palao parece responder claramente al último tercio del s. I a.C. o quizás a comienzos del s. I d.C. (Marco, 1989). 


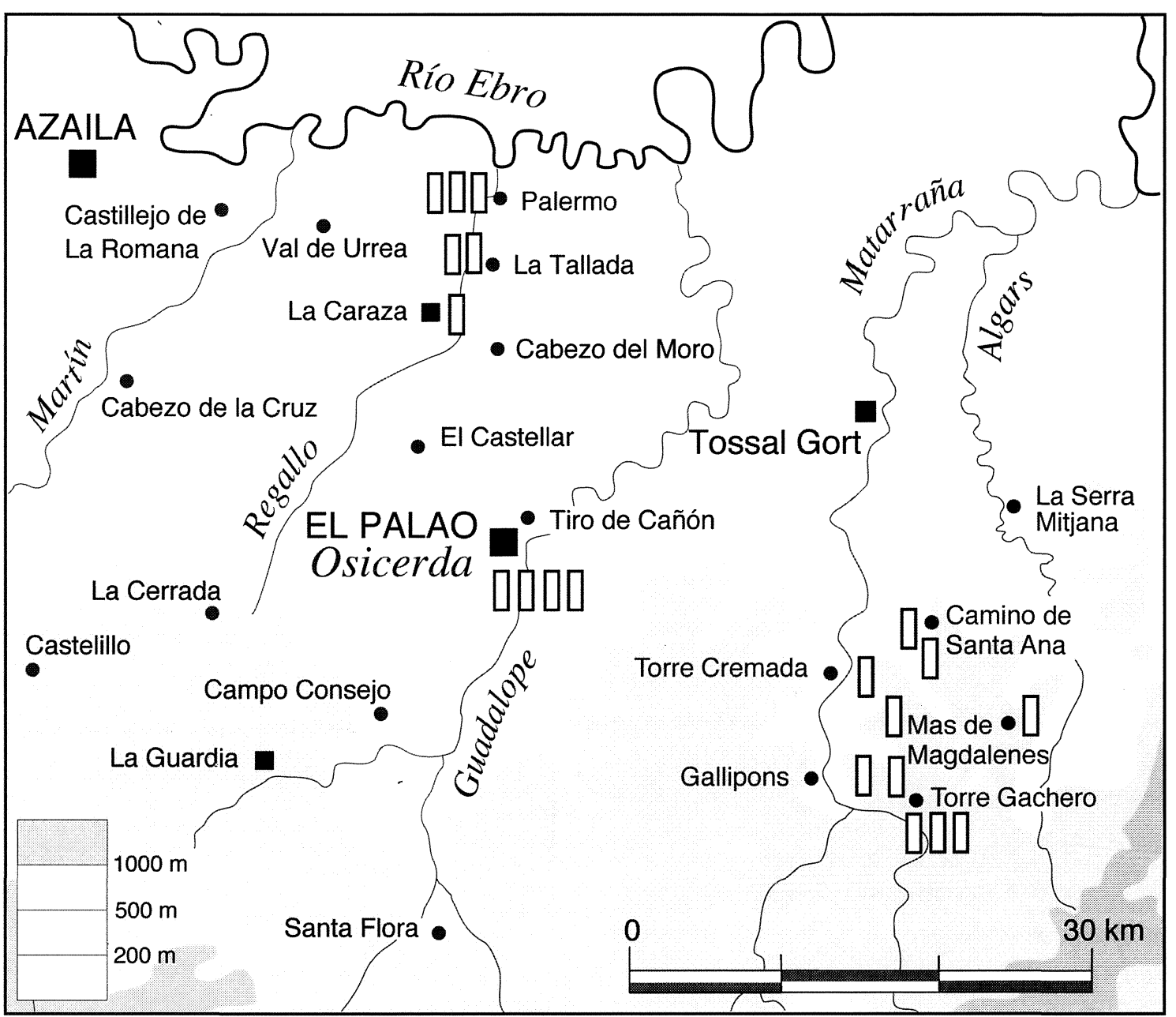

Fig. 6. Distribución del poblamiento en el Bajo Aragón en época republicana. Rectángulos blancos: estelas decoradas del Bajo Aragón.

\section{EL PALAO EN SU TERRITORIO: EL BAJO ARAGÓN IBERO-ROMANO}

El Palao se sitúa en un elevado, extenso y dominante cerro justo en el centro de un territorio que, en un radio aproximado de unos $25-30 \mathrm{~km}$ (distancia que puede recorrerse en una jornada dentro de un terreno relativamente llano como éste) enlaza con los cursos de los ríos Ebro por el Norte, Matarraña-Algars por el Este, Martín por el Oeste y las primeras sierras del Maestrazgo turolense y del Sistema Ibérico por el Sur. Estos accidentes naturales parecen delimitar un territorio que ya aparece bastante bien vertebrado en la fase ibérica plena.

A la vista de las últimas investigaciones (Moret, 2002; Benavente y Moret, 2003), el Ibérico Pleno aparece en el Bajo Aragón como un período de fuerte expansión demográfica en el que se organiza una red de poblados y hábitats rurales densa y bien estructurada. Se han podido distinguir tres niveles: el primero está constituido por unos pocos poblados grandes, de al menos $3.000 \mathrm{~m}^{2}$, como El Cerrao de Valdeltormo, San Antonio de Calaceite o El Mirablanc de Valjunquera. El segundo nivel estaría formado por poblados de 1000 a $2000 \mathrm{~m}^{2}$ cuyos ejemplos más conocidos son El Tossal del Moro de Batea, El Piuró del Barranc Fondo y El Tossal Redó, ambos en Calaceite. El tercer estadio corresponde a hábitats aislados — simples granjas o caseríos-, situados en la llanura o en posiciones no dominantes.

A tenor de esa incipiente jerarquización del hábitat, la población bajoaragonesa de los siglo IV y III a.C. parece agruparse en varios micro-territorios (Ruiz Zapatero y Fernández Martínez, 1984; Moret 


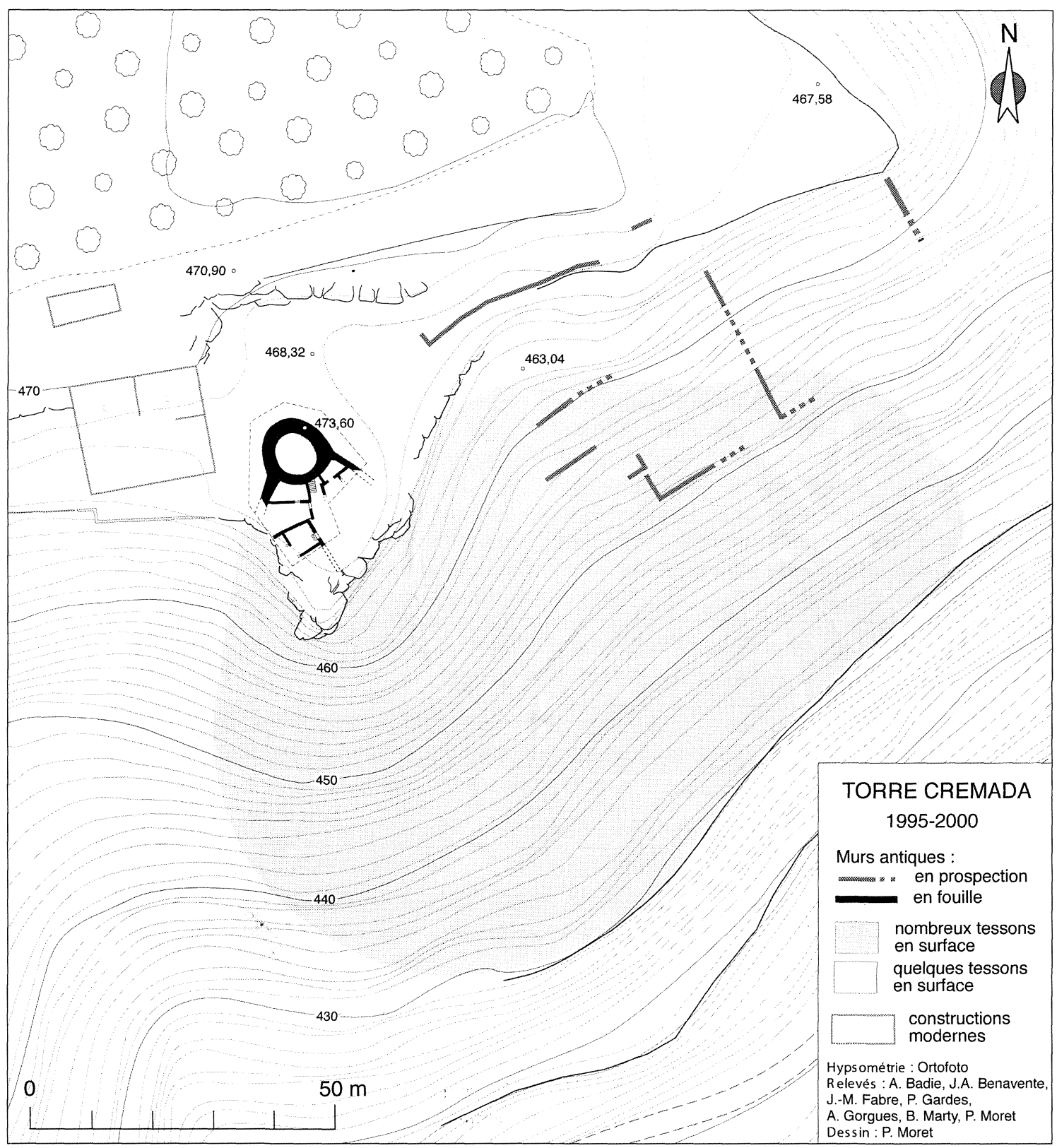

Fig. 7. Plano del yacimiento de Torre Cremada (Valdetormo, Teruel).

y Benavente, 2000; Moret, 2002), con algun asentamiento de mayor tamaño encabezando cada uno de estos territorios, como San Antonio de Calaceite, Els Castellans y Torre Gachero entre el Algars y el Matarraña; El Cerrao y El Mirablanc entre el Matarraña y el Guadalope; Alcañiz el Viejo y Tiro de Cañón en el Guadalope; La Caraza en el Regallo, o la ciudad I de Azaila en el Aguasvivas, entre muchos otros. Sin embargo, ninguno de estos asentamientos mayores alcanzó el tamaño de los oppida ibero-ro- manos del periodo republicano, y su dominio territorial fue mucho más reducido.

- A partir de la conquista romana, y con el inicio de la fase ibérica tardía, comienzan a producirse algunos sensibles cambios. Una buena parte de los asentamientos plenamente ibéricos de la fase anterior son, con el paso del tiempo, paulatinamente abandonados, de manera que, a finales del siglo I a.C., tan sólo se mantienen ocupados en el Bajo Aragón un número muy reducido de asentamientos en 
comparación con los existentes a la llegada de los romanos ${ }^{11}$. Al mismo tiempo que estos asentamientos se abandonan, el poblado de El Palao sigue ocupándose y en pleno crecimiento, convirtiéndose a lo largo del siglo I a.C., con cierta seguridad, en el mayor núcleo urbano del amplio territorio situado entre los ríos Martín, Guadalope y Matarraña (fig. 6). Parece probable, por tanto, que El Palao fuera el principal núcleo receptor de la población que en la primera mitad del siglo I a.C. había abandonado los poblados anteriormente mencionados ${ }^{12}$.

El espacio limitado de este artículo no nos permite ofrecer una relación detallada de los yacimientos ibero-romanos conocidos en las cuencas de los ríos Martín, Guadalope y Matarraña, remitiendo para ello a un trabajo de reciente publicación (Benavente y Moret, 2003). Nos limitaremos a presentar, como ejemplo de asentamiento de segundo orden dentro de este nuevo patrón de ocupación del territorio, el yacimiento de Torre Cremada de Valdeltormo, que ha sido objeto de excavaciones y trabajos de recuperación entre 1995 y 2000 (Moret et alii, 1997; Benavente y Moret, 2002). El yacimiento pertenece en su totalidad a la época republicana (fines del s. II - primera mitad del I a.C.). Los hallazgos han sacado a la luz una torre monumental de planta oval ( $12 \mathrm{~m}$ en el eje mayor), conservando un altura de $6 \mathrm{~m}$. Esta torre está situada en el ángulo norte de un pequeño recinto triangular de $400 \mathrm{~m}^{2}$, sobre un espolón rocoso que domina el Matarraña. Numerosos vestigios de hábitat han aparecido debajo de esta fortificación, en terrazas que cubren una gran parte de la falda entre el reborde rocoso del espolón y el fondo del valle, y con la misma cronología del torreón ${ }^{13}$. Se trata pues de un asentamien-

"En el área de Alcañiz, se abandonan en estos momentos poblados tan importantes como Tiro de Cañón (Perales et alii, 1983-84; Benavente et alii, 1985-86 y 1989), La Caraza de Valdevallerías y Val de las Fuesas, éste último mal conocido.

${ }^{12}$ No obstante, también se ha comprobado que otros poblados más pequeños situados en la misma zona, como el Cabezo del Moro, El Castellar y el Masico de Ponz (en el área del Regallo) o Alcañiz el Viejo, la Redehuerta y la Ermita de San Miguel (en el área del Guadalope) siguen perdurando y probablemente recibiendo también nuevos aportes de población en esa misma época (Benavante, 1984). Asímismo, en las inmediaciones de El Palao se observan numerosos sitios de ocupación de escasa entidad, relacionados muy probablemente con actividades agrícolas y ganaderas dependientes directamente del creciente núcleo urbano, y se sigue ocupando de forma continuada, aunque algo dispersa, la fértil área de la Redehuerta, en las inmediaciones de Alcañiz el Viejo y El Palao.

${ }^{13}$ La hipótesis de una fortaleza militar aislada, que habíamos establecido tras las primeras campañas de excavación (Moret et alii, 1997), debe corregirse a la luz de los hallazgos realizados posteriormente alrededor de la fortificación. to relativamente grande (algo más de una hectárea), establecido en una ladera, bajo el dominio de una potente fortificación (fig. 7). Lo que diferencia profundamente a este conjunto de los poblados ibéricos fortificados tradicionales es el hecho de que la fortificación se reserva a un sector limitado, en posición a la vez dominante y excéntrica, con lo que la fortificación adopta un aspecto francamente monumental, acentuando hasta al hipertrofia el carácter ostentatorio de la torre que constituye su elemento principal.

A la hora de explicar la función de este conjunto fortificado construido hacia el 100 a.C., se presentan dos vías de interpretación. Por un lado, se puede poner el acento en su función militar en el contexto de un política romana de reorganización del territorio a partir de un pequeño número de puntos de apoyo fácilmente defendibles. Torre Cremada habría ejercido este papel en el valle medio del Matarraña, como El Palao en el del Guadalope o incluso Azaila en el del Aguas Vivas. Pero en el caso de Torre Cremada no se entiende bien cuáles debieron de ser los intereses estratégicos de Roma en esta zona marginal, que no fue atravesada por ninguna vía de comunicación importante.

Por otro lado, deben subrayarse los componentes indígenas de este establecimiento, y en este contexto indígena, la torre monumental de Torre Cremada aparece sobre todo como un símbolo de identidad, encarnando los mismos valores guerreros que las estelas inscritas y decoradas con figuras de guerreros y con lanzas. Torres redondas y estelas decoradas parecen ser dos expresiones de un mismo sistema de valores que exalta la función militar y guerrera, fuente de legitimidad esencial para las élites ibéricas. Y si estos valores se exaltan con tanta fuerza, es precisamente porque la guerra ya no se permite a los iberos (salvo en tanto que soldados auxiliares); pasando del horizonte de lo vivido al de lo imaginario, toma en la iconografía y en la arquitectura militar hipertrofiada el lugar que ya no tiene en la realidad. La aristocracia indígena jugó probablemente un papel mayor en ese proceso. Esta fortificación no podía albergar sino a un número reducido de personas: no soldados o guardas, sino - a juzgar por la calidad y la variedad de la vajilla exhumada- las familias dominantes del poblado. Una separación tan neta entre dos sectores del hábitat no existe en las aglomeraciones prerromanas de la región. Una evolución similar puede observarse, por otro lado, en otros sitios de la zona. La hemos indicado antes a propósito de El Palao y de La Caraza, cuyos oppida están separados en dos partes por un foso. Una configuración distinta ha sido puesta en 
evidencia por Asensio en el valle medio del Ebro, donde los oppida de fines del s. II a.C. se componen de una ciudadela fortificada situada en altura, que contiene los principales espacios cívicos y religiosos de la ciudad, y una vasta zona de hábitat no fortificada que se extiende en las faldas o a los pies de la colina (Asensio, 1995).

En líneas generales, se comprueba que desde finales del siglo III a.C. hasta mediados del siglo I a.C. se produce un continuado proceso de abandono de los asentamientos ibéricos hasta entonces existentes a lo largo de las cuencas fluviales del Bajo Aragón, proceso que afecta principalmente a los poblados de pequeño tamaño situados en altura, alejados de las vías de comunicación y de las tierras más fértiles. Al mismo tiempo que se abandonan los antiguos poblados se crean otros nuevos, como Torre Cremada y Camino de Santa Ana en el río Matarraña, El Palao en el río Guadalope, el Castillejo de La Romana de La Puebla de Híjar en el río Martín, o El Cabezo de Alcalá de Azaila en el Aguasvivas (en este último caso, sobre un asentamiento precedente). Estos nuevos asentamientos adquirirán a partir del siglo II a.C. un papel preponderante y vertebrador en la nueva organización romana del territorio bajoaragonés, y esta estrategia de recomposición del territorio parece responder a la vez al deseo de integración de las élites indígenas y al propósito de eficacia administrativa por parte de Roma.

En lo que concierne a El Palao, la elección como lugar de poblamiento de un cerro elevado, divisable desde un gran radio de distancia y claramente dominante sobre su entorno inmediato, indica una evidente intención de control o dominio del extenso territorio circundante. Quizás no sea aventurado pensar, por tanto, que la elección de El Palao como lugar principal de poblamiento de esta zona central del Bajo Aragón pudiera obedecer a un programa de reorganización del territorio directamente relacionado con el control administrativo de este sector del Valle del Ebro por parte de los romanos ${ }^{14}$.

El Palao entraría, por tanto, dentro de la órbita de la nueva organización y planificación territorial, militar y administrativa impuesta por los romanos en su conquista del Valle del Ebro y jugaría un papel decisivo en los dos próximos siglos adquiriendo, muy probablemente, el carácter de «capital» de gran

\footnotetext{
${ }^{14}$ Sobre el tema de la fundación o promoción de «ciudades» como sistema de control del territorio por parte de los romanos en el Valle del Ebro, especialmente en la segunda mitad del siglo II a.C, véase Beltrán Lloris, F. Martín Bueno y Pina Polo, 2000
}

parte del área bajoaragonesa. Según la hipótesis de Jacob (1988), completada y precisada por Burillo (2001-2002), dicha área habría pertenecido al pueblo de los Ausetani del Ebro, pasando luego, después de la conquista romana y de la posterior reorganización del territorio provincial, a formar parte de la Sedetania (Beltrán Lloris, M., 1996).

\section{SOBRE VSEKERTE/OSICERDA, AVSETANI, *OSITANI.}

Queda un problema que, en el estado actual de nuestros conocimientos, no puede ser definitivamente resuelto: el del nombre antiguo de El Palao. Dos posibilidades merecen ser consideradas: que se trate de Orosis, ciudad que acuña moneda y que tenemos que localizar en el Bajo Aragón, o bien que se trate de Osicerda, la ciudad mencionada, al igual que Leónica, por Ptolomeo (II, 6, 62) como ciudad sedetana, y por Plinio (n.h., III, 24) entre los oppida ciuium Latinorum ueterum del Convento caesaraugustano. Monedas de Orosis y de Osicerda han aparecido en El Palao. La posible mención (defendida por Villar, 1991) de la ciudad de Orosis en la gran inscripción celtibérica de Peñalba de Villastar en honor del dios Lugus (Marco, 1986; Untermann, 1997, K.3.3) ha hecho que se proponga su ubicación en el no lejano yacimiento de La Caridad de Caminreal (Burillo, 2002, 213-214).

Como es sabido, el topónimo Usekerte se menciona tal vez como origo de likinete en la inscripción del mosaico de La Caridad de Caminreal (Untermann, 1990, E.7.1), en una época anterior a las emisiones monetales ibero-latinas. Éstas, con la leyenda usekerte/OSI, copian en ases y semises, para conmemorar la batalla de Ilerda, los denarios cesarianos del 49/48 que celebran la conquista de las Galias (García-Bellido y Blázquez, 2001, 399): Victoria con corona y palma en el anverso sobre OSI y, en el reverso, un elefante pisando a la serpiente cornuda (o un carnyx galo con la forma de tal) encima de la leyenda usekerte. La ciudad acuñará en época de Tiberio, como MVN. OSICERDA, ases y semises con la cabeza del emperador en el anverso y el consabido toro a la derecha en el reverso.

$\mathrm{Se}$ ha propuesto localizar a Osicerda en La Caraza de Val de Vallerías (Alcañiz); entre los ilergetes, por la confluencia del Cinca y del Segre y, tan sólo por un improbable parentesco lingüístico, en Osera (Zaragoza). La aparición de una inscripción en la Puebla de Híjar (Teruel) fechable en el último tercio del s. I o en el II, con la mención de unos [in]colis Osicer[densibus] -es decir, de unas per- 
sonas que residían en la ciudad pero que no eran ciudadanas de la misma-, sería en opinión de F. Beltrán un argumento sólido para ubicar la ceca con seguridad en los alrededores inmediatos de dicha localidad turolense, incluyendo el curso inferior del río Martín (Beltrán Lloris, F., 1996, 291). Sin embargo, otros investigadores, como Burillo, la sitúan en la zona de Alcañiz, donde a mediados del siglo I a.C. el principal asentamiento ibero-romano de esta zona era, sin duda alguna, El Palao, y han propuesto su identificación con esta ciudad (Burillo, 1998, 329; 2001, 196; 2001-2002, 186; 2002 a, 204, fig. 2; 2002 b, 217, fig. 6).

La inscripción de la Puebla de Híjar menciona, efectivamente, a unos incolae de Osicerda, pero de ello no se deduce necesariamente la localización de Osicerda en el lugar en la que tal epígrafe aparece (aunque sí que éste se exhibiría en el territorio de la ciudad). Por un lado, no existen en ella estructuras arqueológicas relacionables con una ciudad de este tipo, un municipio de derecho latino. Como más arriba se dijera, el único conjunto de la zona cuyas características pudieran hacer pensar en una ciudad es el Cabezo de la Romana, pero, como han confirmado las excavaciones de M. Beltrán, fue destruido en las Guerras Sertorianas. Por otra parte, puede ser ilustrativo recordar que la res publica Leserensis fue identificada por Alföldy con El Forcall (Castellón) a partir, precisamente, de un epígrafe aparecido no en esta localidad, sino a $6 \mathrm{kms}$., en Vespa (Morella) (Alföldy, 1977; Burillo, 2001-2002, 186). La distancia que separa el lugar del hallazgo de la lápida de La Puebla de Híjar de El Palao de Alcañiz es de unos $25 \mathrm{kms}$., no excesiva (especialmente si tenemos en cuenta lo relativamente llano de la geografía) para considerar que, en el caso de que hubiese sido erigida in situ, el lugar de aparición del monumento formaría probablemente parte del territorium Osicerdense ${ }^{15}$. Los no abundantes hallazgos mone-

${ }^{15}$ Como formaba parte del territorium Leserense el lugar en el que se halló el altar que la res publica Leserensis consagra a Iuppiter Conservator (CIL II 4052), si bien existe la posibilidad de que fuera trasladado desde El Forcall (Alföldy, G., 1977, 16). De hecho, de acuerdo con los datos informatizados de la Universidad de Heidelberg (Epigraphische Datenbank Heidelberg), son excepcionales las inscripciones que consignan el epíteto urbano de los incolae. De los 24 casos atestiguados en la Bética (la provincia con un mayor número de testimonios), tal cosa sucede sólo en dos epígrafes individuales de Aurgi, uno de ellos de origo tuccitana (CIL II $-2^{\mathrm{a}}$ ed. $-, 05,00035$ y $00041=$ HD017847 y 029576). Los otros dos casos existentes en Italia o en las provincias más relacionadas con Hispania consultadas mencionan el término incolae acompañado de un calificativo de origo (los Salassi incolae de Augusta Pretoria -Aosta-: HD 012509) o bien en otra localidad distinta de la que son residentes (los incolis col(oniae) Aventicensium - Avenches, Suiza- documenta- tales de la ceca de Osicerda apuntan, además, hacia el área de Alcañiz, razón por la cual ya Masdeu proponía buscar la ciudad al oeste de ésta (Beltrán Lloris, 1996, 292), es decir, en la zona de El Palao, y las colecciones alcañizanas contienen ejemplares de monedas de Osicerda (Benavente, 1987, 93).

La cronología que hemos propuesto para el fin del uso de la cisterna de El Palao, a fines del período julio-claudio (Marco Simón et alii, 2003), coincide perfectamente con el abandono total o parcial, durante la «crisis flavia», de otras ciudades de Aragón (como Celsa, Bursao, Contrebia Belaisca, San Esteban del Poyo del Cid) o del nordeste de la Península, como Baetulo, Emporiae o Blandae (datos en Beltrán Lloris, M. et alii, 1998, 727-732). No parece que la mención que hace Ptolomeo (II, 6, 62) de Osicerda como ciudad sedetana en el s. II y la existencia en Tarraco de dos lápidas dedicadas a personas de tal origo dificulten grandemente la posibilidad de identificar El Palao con Osicerda ${ }^{16}$. También Ptolomeo (II, 6, 67) menciona a Celsa (ciudad que, a juzgar por la arqueología, tendría su final en época neroniana: Beltrán Lloris, M. et alii 1998), y se documenta igualmente en la epigrafía saguntina un epígrafe funerario de Decimus Cornelius Celsus, edil y dunviro de Celsa, datable, por la paleografía y el tipo de documento, a fines del s. I o comienzos del s. II (Corell, 2002, 139-141); es decir, con una cronología similar a la del epígrafe del osicerdense Cornelius Romanus.

En resumen, mientras que no se ha encontrado un yacimiento con las características arqueológicas necesarias para ubicar Osicerda en La Puebla de Híjar, el único yacimiento que, hasta el presente, parece reunir todas las circunstancias para dicha identificación es, como indicara Burillo (2001-2002, 186), El Palao de Alcañiz. El hibridismo cultural que se manifiesta a través de las acuñaciones bilingües de usekerte/Osicerda se adecuaría con ese mantenimiento de la memoria cultural que hemos señalado para esa ciudad «atípica» que es El Palao a través de sus talleres escultóricos. En todo caso la cuestión sigue abierta y no existen, por el momento, hallazgos o datos totalmente seguros para identificar El Palao con Osicerda.

Hechas estas consideraciones, existe quizás una relación entre el problema de los Ausetani del Ebro y el de Osicerda. Como antes se ha indicado, las monedas nos dan variantes distintas de este nombre: Osicerda en latín en las acuñaciones de época de Tiberio, usekerte en ibérico y $O S I$ en latin en las monedas bilingües más antiguas (Untermann, 1975,

dos en un epígrafe de Minnodunum -Moudon-: $H D$ 022839). 
A.26). Osi (use en ibérico) quizás no sea una simple abreviatura. Podría tratarse del elemento principal del topónimo, teniendo kerte, en segunda posición, un valor de sufijo ${ }^{17}$. Si se acepta esta hipótesis, el étnico derivado de este nombre podría ser restituido bajo la forma *Ositani.

Un etnónimo que se expresara de esta forma podría perfectamente haber sido confundido en ciertas fuentes romanas con el de los Ausetani de la Cataluña interior, cuya capital era Ausa. La duda entre el diptongo $a u$ y la vocal $o$ es patente en Tito Livio a propósito de una ciudad andaluza (Jaén) que cita tanto Auringis (XXIV, 42, 5) como Orongis (XXVIII, 3, 2) ${ }^{18}$. La confusión entre Ausetani (capital Ausa) y Ositani (capital Osi u Osicerda) no sería, en consecuencia, sorprendente. Se la puede imputar a un simple despiste de Tito Livio o de sus fuentes analísticas, o bien a un deseo consciente de armonizar y de simplificar el relato histórico suprimiendo la dualidad de dos etnónimos casi homónimos, pertenecientes a la misma región e implicados en los mismos sucesos históricos. Esta simplificación parece convenir al espíritu de unos historiadores griegos y romanos a los que repugnaba citar demasiados nombres extraños o malsonantes de pueblos bárbaros, con el pretexto de que su acumulación «haría la narración confusa e incomprensible» (Pol., III 36, 34; en el mismo sentido, Str., III 3, 7). En resumen, tendríamos el doblete siguiente:

Ausa (ause en ibérico ${ }^{19}$ ) > Ausetani

Osi (use en ibérico) $>*$ Ositani $>$ Ausetani por asimilación.

${ }^{16}$ La primera, actualmente desaparecida, está dedicada por L. Numisius Montanus a su esposa Porcia Materna, nacida en Osicerda y flamínica provincial de la Hispania Citerior. La tipología de este pedestal de estatua se documenta desde comienzos de época flavia hasta entrado el s. II, y éste en concreto podría datarse en época adriánea, cuando el dedicante desempeñó el flaminado provincial (CIL II4241; Alföldy, $\left.1975,178, n^{\circ} 325\right)$. Estos Porcii se atestiguan, además de en un posible gran mausoleo de Chiprana (Fatás y Martín-Bueno 1977, núm. 17), en un altar funerario de Alcañiz (Bardavíu y Thouvenot, 1930), lo cual parece ciertamente interesante a la hora de plantear la relación de El Palao con Osicerda. La segunda lápida tarraconense es el epígrafe funerario inscripción de Lucius Cornelius Romanus, flamen y dunviro de Osicerda y de Tarraco, y puede datarse por el tipo de letras en época flavia o en la primera mitad del s. II (CIL II 4267; Alföldy, 1975, 187-188, n 341, lám. XL 1).

${ }^{17}$ Se encuentra el elemento kerte en primera posición en la leyenda kertekuntede una dracma ibérica imitando las de Emporion (Untermann, 1975, A.6.06).

18 Inscripciones de época imperial (CIL II, 3360, 33633364, 3366-3370) permiten restituir Aurgi.

${ }_{19}$ De acuerdo con la leyenda monetal ausesken (Untermann, 1975, A.7), en la que se admite que hay que distinguir un radical ause y un sufijo étnico-sken.
Si esta relación entre Osicerda y los Ausetani del Ebro se confirmara, sería un argumento más para localizar a éstos últimos en el Bajo Aragón.

En definitiva, y en relación con El Palao, se siguen planteando una serie de incógnitas, por el momento de difícil resolución, que historiadores y arqueólogos deberán tratar de resolver conjuntamente en el futuro. Entre ellas podemos resumir algunas. Así, el nombre antiguo de El Palao; su ascenso, inducido al parecer por Roma, quizás en relación con el control de los ausetanos y la inclusión de su territorio en la Sedetania; las razones por las que, a diferencia de otros poblados ibero-romanos del valle del Ebro, no fue afectado por las Guerras Sertorianas, o el alcance de los aportes poblacionales de centros que desaparecieron en el s. I a.C. Es de esperar que los futuros trabajos desarrollados en el yacimiento contribuyan a resolver algunos de esos problemas.

\section{BIBLIOGRAFÍA}

ABÁSOLO, J.A. y MARCO, F., 1995: Tipología e iconografía en las estelas de la mitad septentrional de la Península Ibérica, en BELTRÁN, F. (ed.), Roma y el nacimiento de la cultura epigráfica en Occidente, Zaragoza, 327-359.

AlfAYÉ VILlA, S., e.p.: Rituales de aniquilación del enemigo en el monumento ibérico de Binéfar (Huesca), en XXVII Congreso Internacional GIREA - ARYS VIII: «Jerarquías religiosas y control social en el mundo antiguo». Valladolid, 7 9 de noviembre de 2002.

ALFÖLDY, G., 1975: Die römischen Inschriften von Tarraco, Berlin.

AlFÖLDY, G., 1977: Res publica Leserensis (Forcall, Castellón), Servicio de Investigación prehistórica, Valencia.

Almagro-GorbeA, M., 1999: Las fíbulas de jinete y de caballito. Aproximación a las elites ecuestres y su expansión en la Hispania céltica, Zaragoza.

Almagro-GorbeA, M. y LORRIO, A., 1992: Representaciones humanas en el arte céltico de la Península Ibérica, Actas del II Symposium de Arqueología Soriana. Homenaje a D. Teógenes Ortego y Frías, 19-21 de octubre de 1989, I, Soria, 411-451.

Asensio Esteban, J. A., 1995: La ciudad en el mundo prerromano en Aragón, Zaragoza, Institución Fernándo el Católico.

BARDAVÍU PONZ, V., 1926: Los poblados ibéricos de Alcañiz en la cuenca del Guadalope y del Re- 
gallo o Valmuel. Publicaciones de la Academia de Ciencias, Zaragoza.

BARDAVÍU PonZ, V. y Thouvenot, R., 1930: Fouilles dans la région d'Alcañiz (province de Teruel). I. Alcañiz el Viejo - II. El Palao - III. Cabezo del Moro, Bibliothèque de l'Ecole des Hautes Etudes Hispaniques, XI (2), Bordeaux.

BELTRÁN LLORIS, F., 1996: Una liberalidad en La Puebla de Híjar (Teruel) y la localización del municipium Osicerda, Archivo Español de Arqueología, 69, p. 287-294.

Beltrán Lloris, F., MARTín Bueno, M. y PinA Polo, F., 2000: Roma en la Cuenca Media del Ebro. La Romanización en Aragón, Zaragoza.

BELTRÁn LlORIS, M., 1996: Los Iberos en Aragón, Zaragoza.

BELTRÁN LlORIS, M., et alii, 1998: Colonia Victrix Iulia Lepida-Celsa (Velilla de Ebro, Zaragoza). III,1-III,2. El instrumentum domesticum de la «Casa de los Delfines», Zaragoza.

Benavente SerRano, J.A., 1983-1984: El poblamiento ibérico en el valle medio del Regallo (Alcañiz, Teruel), Kalathos, 3-4, 155-190.

BENAVENTE SERRANO, J.A., et alii, 1985-1986: Tiro de Cañón (Alcañiz): Materiales cerámicos II, líticos, metálicos y óseos, Kalathos, 5-6, 107-152.

BenAVENTE SERRANO, J.A., et alii, 1989: Catálogo de la colección arqueológica de los Padres Escolapios de Alcañiz (Teruel), Zaragoza, Diputación General de Aragón.

Benavente Serrano, J.A., 1987: Arqueología de Alcañiz. Síntesis de Arqueología de Alcañiz y su entorno, Diputaciớn General de Aragón, Zaragoza, 1987.

Benavente Serrano, J.A. y Moret , P., 2002: El poblado ibérico tardío de Torre Cremada (Valdeltormo, Teruel). Un hábitat fortificado del siglo I a.C. en el Bajo Aragón, en I Jornades d'Arqueologia - Ibers a l'Ebre. Recerca i interpretació, Tivissa, 23-24 novembre 2001 (Ilercavònia, 3), Tivissa, 221-228.

Benavente Serrano, J.A. y Moret, P., 2003: El Palao en el contexto del Bajo Aragón íbero-romano, en MARCO, F. et alii, El poblado iberoromano de El Palao (Alcañiz, Teruel). La cisterna, Al-Qannis, 10, 7-23.

Benavente Serrano, J.A., Navarro, C., Ponz, J.L. y VILlaAnUEVA, J., 1991: El poblamiento antiguo del área endorreica de Alcañiz (Teruel), $A l$ Qannis, 2, 36-92.

Benavente Serrano, P., Dobato, A. y BenavenTE, J.A., 1991: Informe sobre el levantamiento planimétrico y altimétrico del poblado íbero-ro- mano de El Palao (Alcañiz, Teruel), Arqueología Aragonesa 1986-1987, Zaragoza, 175-178.

BuRILlo MozotA, F., 1992: Las necrópolis de época ibérica y el ritual de la muerte en el valle medio del Ebro, en BLÁNQUEZ, J. y ANTONA, A. (coords.), Serie Varia 1, Congreso de Arqueología ibérica. Las necrópolis, U.A.M., Madrid, 563-586.

Burillo Mozota, F., 1998: Celtíberos. Etnias y estados, Barcelona.

Burillo Mozota, F., 2001: Etnias y poblamiento en el área ibérica del valle medio del Ebro: Sedetanos y edetanos, en BERROCAL, L. y GARDES, Ph. (eds.), Entre celtas e íberos. Las poblaciones protohistóricas de las Galias e Hispania, Real Academia de la Historia-Casa de Velázquez, Madrid, 187-200.

Burillo Mozota, F., 2002 a: Etnias y fronteras: Sobre el límite oriental de los celtíberos, en M. Molinos y A. Zifferero (eds.), Primi popoli d'Europa. Proposte e riflessioni sulle origini della civiltà nell'Europa mediterranea, All'Insegna del Giglio, 2002, 201-219.

Burillo Mozota, F., 2002 b: Oppida, ciudades estado y populi en la transición del Ibérico Pleno al Tardío en el nordeste de la Península Ibéric, I Jornades d'Arqueologia - Ibers a l'Ebre. Recerca i interpretació, Tivissa, 23-24 novembre 2001 (Ilercavònia, 3), Tivissa, 205-220.

Burillo MozotA, F., 2001-2002: Propuesta de una territorialidad étnica para el Bajo Aragón: los Ausetanos del Ebro u Ositanos, Kalathos 20-21 (Teruel 2001-2002), 159-187.

Comas, M.; Padrós, P. y Velaza, J., 2001: Dos nuevas estelas ibéricas de Badalona, Palaeohispanica, 1, 291-299.

CORELl, J., 2002: Inscripcions romanes del País Valencià. Ia. Saguntum i el seu territori, Fonts històriques valencianes 12, València.

DíAZ SANZ, Ma A., 1989: Sacrificios humanos en la celtiberia oriental: las cabezas cortadas, en II Encuentro de Estudios Bilbilitanos, vol. I, Calatayud, 33-41.

Domínguez Monedero, A., 1994: De nuevo sobre la estela funeraria de Ampurias, en DE LA CASA, C. (ed.), V Congreso internacional de Estelas Funerarias (Soria, 1993), Soria, 55-62.

FERNÁNDEZ FUSTER, L., 1951: Las estelas ibéricas del Bajo Aragón, Seminario de Arte Aragonés III, Zaragoza, 5-20.

GALÁN, E., 1994: Estelas y fronteras: un caso de estudio en el bajo Aragón en época ibérica, en DE LA CASA C. (ed.), V Congreso internacional de Estelas Funerarias (Soria, 1993), Soria, 99-106. 
Garcés Estallo, I. y Cebrià Escuer, A., e.p.: L'estela ibèrica de Tona (Osona), Pyrenae 33-34 (2002-2003).

García-Bellido, C. y BlázQuez, C., 2001: Diccionario de cecas y pueblos hispánicos. Volumen II: Catálogos de cecas y pueblos, Madrid.

IZQUIERDO, I. y ARASA, F., 1999: La imagen de la memoria. Antecedentes, tipología e iconografía de las estelas de época ibérica, Archivo de Prehistoria Levantina, XXII, 259-300.

JACOB, P., 1988: Un doublet dans la géographie livienne de l'Espagne antique: les Ausétans de l'Ebre, Kalathos, 7-8, 135-148.

MARCO SimÓN, F., 1976: Nuevas estelas ibéricas de Alcañiz (Teruel), Pyrenae, 12, 73-90.

MARCo Simón, F., 1978 a: Estelas decoradas de los Conventos Caesaraugustano y Cluniense (Caesaraugusta, 43-44), Zaragoza.

Marco Simón, F., 1978b: Dos esculturas ibéricas zoomorfas de El Palao (Alcañiz, Teruel), Els Orígens del món ibèric, Barcelona, 407-414.

Marco Simón, F., 1980: Excavaciones en El Palao (Alcañiz, Teruel). Campaña de 1979, Caesaraugusta 51-52, 153-185.

MARCO Simón, F., 1982: Sobre algunas aras romanas de Alcañiz (Teruel), Kalathos II, 33-46.

MARCO SIMÓN, F., 1983: El yacimiento ibero-romano de El Palao (Alcañiz, Teruel). Campaña de 1980, Casaraugusta, 57-58, pp. 23-50.

MARCo Simón, F., 1983-84: Consideraciones sobre la religiosidad ibérica en el ámbito turolense, Kalathos 3-4, 71-93.

MARCo Simón, F., 1985: Excavaciones en El Palao (Alcañiz, Teruel). Campaña de 1982, Noticiario Arqueológico Hispánico, 1985, 193-218.

MARCO Simón, F., 1989: Objetos escultóricos Colección PP. Escolapios de Alcañiz, Catálogo de la Colección Arqueológica. Alcañiz, 1989, 171184.

MARCO SIMÓN, F., 1994: La religión indígena en la Hispania indoeuropea, en BLÁZQUEZ, J.M. et alii, Historia de las religiones de la Europa antigua, Madrid, 313-400.

MARCO Simón, F. et alii, 2003: El poblado iberoromano de El Palao (Alcañiz, Teruel). La cisterna, en Al Qannis 10.

MARCo Simón, F. y BALdellou, V., 1978: El monumento ibérico de Binéfar (Huesca), Pyrenae 12 (1976), Barcelona, 1978, 91-116.

MARCo Simón, F. y Floría, A., 1986: Sobre una escultura zoomorfa ibérica y otros restos procedentes de la antigua Tolous, Caesaraugusta, 63, 69-86.

Medrano Marqués, M. y Diaz SAnZ, Ma A.,
2000: Novedades acerca de las ciudades de Contrebia Belaisca y Nertobriga, Salduie 1, 165-180.

MORET, P., 2002: Reflexiones sobre el período ibérico pleno (siglos V a III a.C.) en el Bajo Aragón y zonas vecinas del curso inferior del Ebro, en $I$ Jornades d'Arqueologia - Ibers a l'Ebre. Recerca i interpretació, Tivissa, 23-24 novembre 2001 (Ilercavònia, 3), Tivissa, p. 111-136.

MoreT, P., 2003: Fortifications ibériques tardives et défense du territoire en Hispanie citérieure, en Defensa y territorio en Hispania de los Escipiones a Augusto (Coloquio Internacional, Madrid, 19-20 de marzo de 2001), Casa de Velázquez Universidad de León, en prensa.

Moret, P. y BenAVEnTE, J.A., 2000: Nouvelles recherches sur l'habitat de l'âge du Fer dans la vallée du Matarraña (Bas Aragon). Actas do III Congresso de Arqueologia Peninsular, vol. 5, «Proto-História da Península Ibérica», Porto, 327-344.

Moret, P., Benavente, J.A., y Gorgues, A., e.p.: El poblamiento ibérico en el valle medio del Matarraña. Investigaciones arqueológicas en Valdeltormo (Teruel), 1995-2000, Al-Qannis, 11.

Moret, P., Gardes, A. y Benavente J.A., 1997: La Torre Cremada (Valdeltormo, Teruel): un fortín ibero-romano en el Bajo Aragón, Kalathos, $16,19-44$.

Moret, P., Gorgues, A. y Ruiz-Darasse, C., e.p.: Cinq nouvelles inscriptions sur céramique du Bas Aragon et de la Terra Alta, Palaeohispani$c a, 3$.

Perales García, M.P., Picazo, J.V. y SANCho, A., 1983-1984: Tiro de Cañón (Alcañiz): los materiales cerámicos. I, Kalathos, 3-4, 203-258.

QUESADA SANZ, F., 1994: Lanzas hincadas, Aristóteles y las Estelas del Bajo Aragón, en DE LA CASA, C. (ed.), V Congreso Internacional de Estelas Funerarias, 1, Soria, 361-369.

Quesada SANZ, F., 1999-2000: Territorio, etnicidad y cultura material. Estelas «Del Bajo Aragón» en Cataluña Nororiental», Kalathos 18-19, 95106.

RodRÍGUEZ RAMOS, J., 1997: Primeras observaciones para una datación paleográfica de la escritura ibérica, AEspA 70, 13-30, 25-26.

RUANO, E., 1990: Fragmentos de estela con relieves procedente de Mas de las Matas (Teruel), GEMA $X$, Mas de las Matas, 97-110.

Ruiz Zapatero, G. y Fernández Martínez, V., 1984: Patrones de asentamiento en el Bajo Aragón protohistórico. Arqueología Espacial, 4, Teruel, p. 43-63. 
SÁIz Ríos, P., 1992: Cabeza cortada, en BELTRÁN LLORIS, M. et alii, Arqueología 92, Zaragoza, 193-194.

SoPeÑa GenZOR, G., 1995: Ética y ritual. Aproximación al estudio de la religiosidad de los pueblos celtibéricos, Zaragoza.

UntermanN, J., 1975: Monumenta Linguarum Hispanicarum, I: Die Münzlegenden, Wiesbaden.

UNTERMANN, J., 1990: Monumenta Linguarum Hispanicarum, III. Die iberischen Inschriften aus Spanien, Wiesbaden.

UNTERMANN, J., 1997: Monumenta Linguarum His- panicarum. IV. Die tartessischen, keltiberischen und lusitanischen Inschriften, Wiesbaden.

VICENTE REDÓN, J. et alii, 1986: La ciudad celtibérica de «La Caridad» (Caminreal, Teruel), Teruel.

VILLAR, F., 1991: Le locatif celtibère et le caractère tardif de la langue celtique dans l'inscripcion de Peñalba de Villastar, Zeitschrift für Celtische Philologie 44, 56-66.

VILLAR, F. et alii, 2001: El IV Bronce de Botorrita (Contrebia Belaisca): Arqueología y Lingüística, Salamanca. 